\title{
A Low-Cost Video Game Applied for Training of Upper Extremity Function in Children with Cerebral Palsy: A Pilot Study
}

\begin{abstract}
MICHIEL J. A. JANNINK, Ph.D., ${ }^{1}$ GELSKE J. VAN DER Wilden, M.D., ${ }^{2}$ DORINE W. NAVIS, M.S., ${ }^{1}$ GERBEN VISSER, P.T., ${ }^{2}$ JEANINE GUSSINKLO, P.T., ${ }^{2}$ and MAARTEN IJZERMAN, Ph.D., P.T. ${ }^{1,3}$
\end{abstract}

\begin{abstract}
The aim of the present study was to determine the user satisfaction of the EyeToy for the training of the upper limb in children with cerebral palsy (CP). User satisfaction was measured in 12 children with $\mathrm{CP}$, using a postexperience questionnaire, primarily based on a presence questionnaire. In general, children with $C P$ were satisfied with and motivated by the EyeToy training. In addition, a first evaluation study was performed to determine the effect of this training method on the upper limb function. Ten children with CP were randomly assigned to the intervention (mean age 11 years, 9 months; SD 2,3) and the control group (mean age 12 years, 3 months; $S D$ 3,2). After a treatment period of 6 weeks, the intervention group completed a user satisfaction questionnaire. Functional outcome was measured using the Melbourne Assessment scores. Percentage scores of the Melbourne Assessment of 7 of the 10 children were the same or changed only $1 \%$ to $2 \%$ from baseline to followup. However, in the experimental group, two children improved more, $9 \%$ and $13 \%$ respectively. In conclusion, it can be said that the EyeToy is a motivational training tool for the training of children with $\mathrm{CP}$ and has the potential to improve upper extremity function.
\end{abstract}

\section{INTRODUCTION}

$\mathrm{C}$ erebral palsy (CP) is a clinical syndrome characterized by movement disorders caused by a nonprogressive injury to the immature brain. The prevalence of $\mathrm{CP}$ in Western countries is approximately 2.0 to 2.5 per 1,000 live births. ${ }^{1}$ One of the consequences of $\mathrm{CP}$ is an impaired motor function of the arm and hand. Arm movements, such as reaching and grasping, are essential for various activities of daily life. As such, an important part of rehabilitation treatment is aimed at achieving the maximum functional ability of the impaired arm. To integrate the affected arm in children with $\mathrm{CP}$, it is essential to make rehabilitation treatment more challenging-for example, by integrating play and leisure occupations in therapy. 2,3

It is suggested that computer play, such as virtual reality, could be used in rehabilitation for children with disabilities. ${ }^{4}$ These technologies have several strengths, including the capability of VR to adapt the virtual environment (VE) relatively easily to meet the needs of a user's physical abilities. Other advantages are that children play in a safe environment, preventing injury, ${ }^{5}$ that VR facilitates realtime performance feedback and independent moti-

${ }^{1}$ Roessingh Research and Development, Enschede, Netherlands.

${ }^{2}$ Rehabilitation Centre "Het Roessingh" Enschede, Netherlands.

${ }^{3}$ University of Twente, Faculty Electrotechnics, Mathematics and Informatics, Enschede, Netherlands. 
vational training, and VR has the capacity to increase the complexity of tasks. Despite the promises of VR in rehabilitation, many of the current VR systems have several limitations (e.g., high costs, presence of wires that limit user movements), which hamper implementation in clinical practice. ${ }^{5}$ A VR technique without interaction and wiring problems is motioncapturing VR. This technique is related to the videocapture VR gaming platforms in which users interact with the VEs by making body (mainly arm) movements. The Mandala ${ }^{\circledR}$ Gesture Xtreme (GX) System combined this technique with video game environments. Reid investigated this application in children with $\mathrm{CP} .{ }^{6}$ The children received increased competence, self-assurance, self-esteem, self-worth, and control over the VEs. ${ }^{3}$ They also found that the VR game stimulated playfulness and was a very motivating activity. ${ }^{6}$ Although the Mandala GX System seems suitable for the integration of play and leisure in rehabilitation, it is expensive and is not available off the shelf. A recent product that incorporates motion capturing is the EyeToy application. The game EyeToy: Play is used with the PlayStation 2 platform, which is relatively inexpensive. The aim of this study was to determine user satisfaction of the EyeToy for the training of the upper limb in children with CP. In addition, a first evaluation study was performed to determine the effect of this training method on the upper limb function.

\section{USER SATISFACTION STUDY}

\section{Participants}

Twelve children with $\mathrm{CP}$, treated at a local rehabilitation hospital, were approached to participate in the present user satisfaction study. Before partic- ipation of the children, both children and parents signed an informed consent. The inclusion criteria specified that participants (a) are between 7 and 16 years; (b) have a diagnosis of CP; (c) can understand the Dutch language; and (d) can stretch and bend the shoulder and elbow of their affected arm. The exclusion criteria were (a) a visual or auditory impairment; (b) epilepsy; and (c) mental retardation.

\section{Apparatus}

In this study, the EyeToy: Play (Sony Computer Entertainment Group Europe Ltd.; United Kingdom) was used (Figure 1). The EyeToy: Play consists of a game disc and a USB camera that is plugged into a PlayStation 2 (Sony Computer Entertainment, Inc.; Tokyo, Japan). Based on prior expert interviews with physiotherapists and occupational therapists of the local rehabilitation center, different EyeToy minigames were selected for the training sessions. Within these games, patients had to make gross elbow and shoulder movements to "touch" and manipulate the virtual objects on the television screen.

\section{User satisfaction questionnaire}

Several usability evaluation methods exist, such as thinking aloud tests, questionnaires, interviews, performance tests, focus groups, and heuristic evaluation. ${ }^{7}$ However, the existing evaluation methods, developed for the 2D graphical user interfaces (GUIs), are not appropriate for evaluation of VEs. Therefore, Gabbard specified a taxonomy of usability characteristics specifically for VEs. ${ }^{8,9}$ In addition, Federoff states that satisfaction is more important than effectiveness and efficiency in evaluating game play. ${ }^{10}$ For collecting user satisfaction with the Eye-

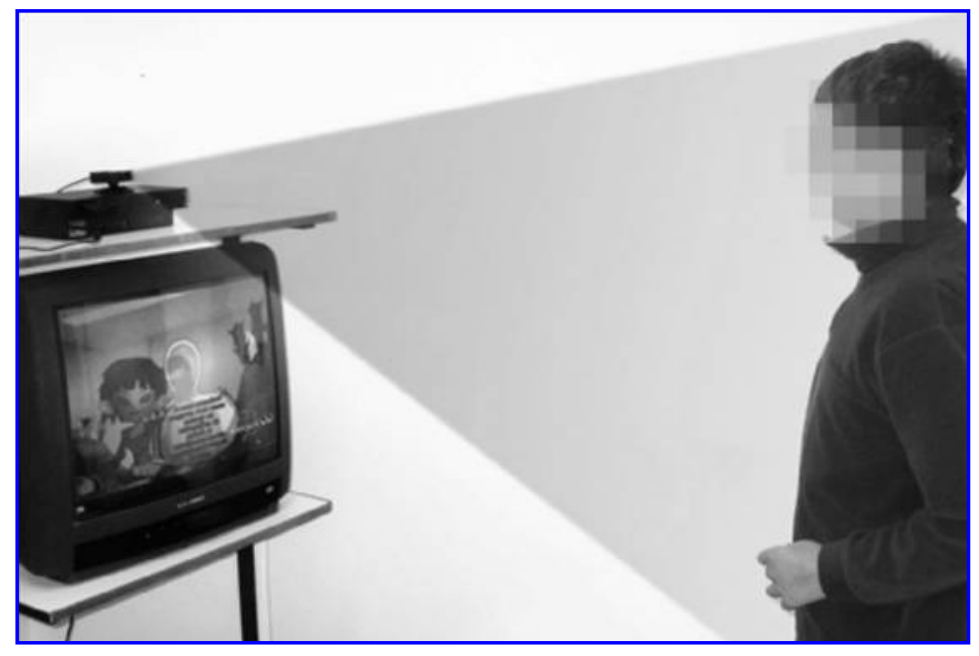

FIG. 1. Child with $\mathrm{CP}$ performing Eye Toy training. 
Toy games, a postexperience questionnaire was developed for the present study. This user satisfaction questionnaire for children with disabilities is primarily based on a presence questionnaire ${ }^{11}$ and additionally on several game play ${ }^{10}$ and VE heuristics. ${ }^{8,9}$ Statements concerning attitudes and feelings toward the EyeToy games and clarity for different aspects of the EyeToy games were presented.

\section{Data analysis}

The questions of the user satisfaction questionnaire were grouped by subject (presentation, level of difficulty, motivation, cognitive abilities, physical effort) and accordingly presented in frequencies.

\section{Results}

Twelve children with CP completed the user satisfaction questionnaire (Table 1). Answers are presented in frequencies.

With respect to visual presentation, the children reported they were able to see all things in the games very well. The moving objects and figures in the games were very interesting and attractive to them. The children experienced no delay between

Table 1. User Satisfaction Questionnaire: Answers in Frequencies $(N=12)$

\begin{tabular}{|c|c|c|c|c|c|}
\hline & 1 & 2 & 3 & 4 & 5 \\
\hline \multicolumn{6}{|l|}{ EyeToy $^{\mathrm{TM}}$ : presentation } \\
\hline I could see all things in the game very well & - & - & - & - & 12 \\
\hline I found the moving things/objects in the game very interesting & - & - & - & 5 & \\
\hline The things I saw in the game were very attractive & - & 2 & - & 4 & \\
\hline There was no delay in what I did and what I saw in the game & - & 2 & - & 2 & 8 \\
\hline I could hear all sounds very well & - & - & - & - & 12 \\
\hline The sounds I heard out of the game were very attractive & - & 3 & - & 4 & 5 \\
\hline I couldn't hear where all sounds out of the game did come from & - & 3 & 2 & 3 & 4 \\
\hline I found it nice to see myself in the game & - & 1 & 4 & 1 & 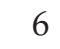 \\
\hline $\begin{array}{l}\text { I would regret it if I wouldn't see myself in the game but, for } \\
\text { example, a cartoon character }\end{array}$ & 1 & 2 & 1 & 5 & \\
\hline
\end{tabular}

EyeToy $^{\mathrm{TM}}$ : level of difficulty

The game was too hard

The game wa so fast, it wasn't too easy; but also wasn't too hard

I still must learn a lot, before I can play this game very well

I could predict what was going to happen after I had made a movement

I had the feeling I could win

$\begin{array}{rrrrr}4 & 5 & - & 3 & - \\ - & 4 & - & 4 & 4 \\ 5 & 4 & 1 & 1 & 1 \\ - & - & - & 1 & 11 \\ 1 & 5 & - & 4 & 2\end{array}$

Player: motivation

I would find it nice if I could play the game together with more children $\quad-\quad 2 \quad \begin{array}{llll}2 & 3\end{array}$
at the same time

I wish I could save the game where I ended, so the next time I can start $\quad \begin{array}{llllll} & 2 & 2 & 2\end{array}$

from there

The game was so attractive that I lost all count of time

I would like to play this game more often

EyeToy ${ }^{\mathrm{TM}}$ training is less fun than regular physiotherapy

Player: cognitive capability

This game was easy to understand

This game was easy to play

It was very logical playing the game by moving my hands

$-1-38$

$-\quad 1 \quad-\quad 2 \quad 9$

Player: physical effort

I found it hard to play the game by moving my hands

I become more tired from this game play than from the regular physiotherapy

By playing the game, I have learned new movements

I think I could learn new movements, by playing the game more often

$\begin{array}{rrrrr}- & - & 1 & 7 & 4 \\ - & 2 & 2 & 4 & 4 \\ - & - & - & - & 12\end{array}$

$1=$ completely disagree; $2=$ slightly disagree; $3=$ neutral; $4=$ slightly agree; $5=$ completely agree 
the movements they made and the reflection of these movements in the VR games. They liked seeing themselves in the games. The experienced level of difficulty varied among the participating children. Overall, the children were motivated to train with the EyeToy. One child explained this was because of "more variation in the EyeToy training." The children were divided about feeling the need to win a game. This feeling was enhanced by the negative feedback of the system after finishing a game. Although some children had learning difficulties, most of them agreed that the games were easy to understand. All children intuitively played the EyeToy games by moving their hands. The questioned children experienced few difficulties with playing the game by moving their hands. Becoming tired because of the therapy did not much differentiate between EyeToy training and regular physiotherapy.

\section{FIRST EVALUATION STUDY: UPPER LIMB FUNCTION}

Methods

Participants. Ten children with CP, treated at a local rehabilitation hospital, were approached by a specialist in physical medicine and rehabilitation to participate in the present study. The research project was approved by the local Medical Ethical Committee. Before participation of the children, both children and parents signed informed consent. The inclusion criteria specified that patients (a) are between 7 and 16 years; (b) have a diagnosis of CP; (c) can understand the Dutch language; and (d) can stretch and bend the shoulder and elbow of their affected arm. The exclusion criteria were (a) a visual or auditory impairment; (b) epilepsy; and (c) mental retardation.

At baseline, the Gross Motor Function Classification System (GMFCS), ${ }^{12}$ the Manual Ability Classification System (MACS), ${ }^{13}$ and Zancolli classification $^{14}$ were used as an indicator of gross motor function, manual function, and hand function respectively.

Apparatus. In the present study, EyeToy: Play, as described previously, was used (Figure 1). Based on expert interviews with physiotherapists and occupational therapists, the following minigames were selected for the VR play sessions: Kung Foo (participants were challenged to hit virtual characters jumping from a Chinese tower), Wishi Washi (participants were challenged to wash virtual windows by making gross arm movements), and Keep Ups

Table 2. Participant Characteristics

\begin{tabular}{llrllccc}
\hline $\begin{array}{l}\text { Child } \\
\text { ID }\end{array}$ & Group & Gender & Age & Diagnosis & GMFCS & MACS & $\begin{array}{c}\text { Zancolli } \\
\text { class }\end{array}$ \\
\hline 01 & Control & M & 14.6 & CP spastic tetraplegia & III & II & I \\
04 & Control & F & 7.0 & CP spastic hemiplegia & I & II & I \\
06 & Control & M & 11.1 & CP spastic tetraplegia & I & II & I \\
08 & Control & M & 10.9 & CP spastic tetraplegia & IV & IV & I \\
09 & Control & M & 15.8 & CP spastic diplegia & IV & III & I \\
02 & Intervention & M & 12.6 & CP spastic diplegia & IV & II & I \\
03 & Intervention & M & 12.8 & CP spastic tetraplegia & IV & IV & I \\
05 & Intervention & M & 16.0 & CP spastic tetraplegia & I & II & I \\
07 & Intervention & M & 13.0 & CP spastic tetraplegia & I & II & I \\
10 & Intervention & M & 7.2 & CP spastic tetraplegia & I & II & I \\
\hline
\end{tabular}

$\mathrm{M}$, male; F, female; $\mathrm{CP}$, cerebral palsy

GMFCS: Level I participants can generally walk without restrictions but tend to be limited in some of the more advanced motor skills. Level V children are very limited in their ability to move themselves around even with the use of assistive technology.

MACS: Level I participants can handle objects easily and successfully, even with limitations in speed and accuracy when performing manual tasks. Level V children can not handle objects and have severely limited ability to perform even simple actions.

Zancolli: Pattern I indicates an active extension of the fingers with the wrist in less than 20 degrees of wrist flexion. A child with pattern III has a severe flexion deformity; no active extension of fingers, even with maximal wrist flexion, can be made. 
(participants were challenged to keep up a virtual ball with their arms).

Outcome measurements. The Melbourne Assessment of Unilateral Upper Limb Function (Melbourne Assessment) was developed to quantify the quality of upper limb function in children between 5 and 15 years old with the diagnosis of CP. ${ }^{15,16,17}$ The assessment consists of 16 items that examine reach, grasp, release, and manipulation of the affected upper limb. The individual subscores were summed to obtain a raw overall score, after which it was converted to a percentage score.

Procedure. Within this explorative study, children were randomly assigned to either the control or the EyeToy game intervention group. After randomization, participants were assessed twice for the Melbourne Assessment: a baseline assessment (T0) and a follow-up assessment after 6 weeks of training (T1). The children assigned to the control group continued with their regular physiotherapy program; the five children in the intervention group used the VR game in addition to their regular physiotherapy. However, the total treatment intensity was equal for both groups: 30 minutes twice a week for 6 weeks. Each child's physiotherapist decided which of the three EyeToy minigames the child should play and in what order.

\section{Results}

Participants. The study population consisted of 10 children with varying types and degrees of $\mathrm{CP}$. The characteristics of the participating children are summarized in Table 2. There were no differences in descriptive measures between the control group $(n=5)$ and the intervention group $(n=5)$.
Upper limb function. The Melbourne Assessment total percentage scores for both baseline and followup of the 10 participants are presented in Table 3. As can be seen, percentage scores of the Melbourne Assessment of 7 of the 10 children were the same or changed only $1 \%$ to $2 \%$ from baseline to followup. In the experimental group, children 5 and 7 improved more, $9 \%$ and $13 \%$ respectively.

\section{DISCUSSION}

The present study showed that the EyeToy has the potential to improve arm function in children with CP. Of the five children in the EyeToy group, two children improved considerably on the Melbourne Assessment total percentage score $(9 \%$ and $13 \%$ ) after following only 6 weeks of EyeToy training with moderate intensity. No negative side effects have been reported. This is in accordance with a study concerning motion-capturing VR games. ${ }^{18}$ A plausible rationale of the advantages of motor learning and relearning by means of VR technology is given by Holden. ${ }^{19}$ She stated that VR has the potential to increase the number of repetitions, include augmented feedback, and motivate patients, which are all important factors for motor learning and related cortical changes.

In general, the children were satisfied with the EyeToy training. This is in accordance with the study of Harris, ${ }^{6}$ who concluded that playing with the Mandala GX System was a motivating activity for children with $\mathrm{CP}$ and consequently could be a successful training method for improving self-esteem, mental health, and physical health and for stimulating social relationships and a sense of selfconcept.

Table 3. Total Percentage Scores for the Melbourne Assessment at T0 and T1

\begin{tabular}{llccc}
\hline $\begin{array}{l}\text { Child } \\
\text { ID }\end{array}$ & Group & $\begin{array}{c}\text { Melbourne score (\%) } \\
\text { T0 }\end{array}$ & $\begin{array}{c}\text { Melbourne score (\%) } \\
\text { T1 }\end{array}$ & $\begin{array}{c}\text { Difference at T1 } \\
(\%)\end{array}$ \\
\hline 01 & Control & 67 & 71 & 4 \\
04 & Control & 70 & 70 & 0 \\
06 & Control & 71 & 70 & -1 \\
08 & Control & 76 & 75 & -1 \\
09 & Control & 86 & 88 & 2 \\
02 & Intervention & 93 & 94 & 1 \\
03 & Intervention & 61 & 61 & 0 \\
05 & Intervention & 73 & 82 & 9 \\
07 & Intervention & 61 & 74 & 13 \\
10 & Intervention & 53 & 55 & 2 \\
\hline
\end{tabular}


However, besides these promising aspects, the EyeToy has limitations for children with motor disorders. Because the technology of such systems is not designed with a rehabilitation purpose in mind, not all the desired adjustments can be made. For example, it is not possible to grade the level of difficulty of the game to the child's capacity and to the stages of rehabilitation. To make the system even more appropriate for rehabilitation purposes, adjustments to the design of the games, the speed of the games, and feedback about performance and results should be implemented to increase motor learning and relearning. The EyeToy is a promising intervention tool for the training of upper extremity function in children with physical disabilities. The VR game has the potential to improve upper extremity function, and provides at the same a more motivational training. However, adaptations to the system and accompanying VR games are necessary to make it more suitable for children with $\mathrm{CP}$.

\section{ACKNOWLEDGMENT}

This study was supported by the National Centre for Innovation in Rehabilitation Technology, Netherlands.

\section{REFERENCES}

1. SCPE prevalence and characteristics of children with cerebral palsy in Europe. Developmental Medicine and Child Neurology 2002; 44(9):633-40.

2. Boyd R, Morris M, Graham H. Management of upper limb dysfunction in children with cerebral palsy: a systematic review. European Journal of Neurology 2001; 8 (suppl. 5):150-166.

3. Miller S, Reid D. Doing play: competency, control, and expression. Cyberpsychology \& Behavior 2003; 6:623-32.

4. Brodin J, Jonson U. Computer play centres for children with disabilities. International Journal of Rehabilitation Research 2000; 23:125-8.

5. Rizzo A, Kin G. A SWOT analysis of the field of VR rehabilitation and therapy. Presence: Teleoperators and Virtual Environ 2005; 14:119-46.

6. Harris K, Reid D. The influence of virtual reality play on children's motivation. Canadian Journal of Occupational Therapy 2005; 72:21-9.

7. Nielsen J, Mack R. (1994) Usability inspection methods. New York: Wiley.

8. Gabbard J. (1997) A taxonomy of usability characteristics in virtual environments. Available at: http:// scholar.lib.vt.edu/theses / available/etd-111697121737/unrestricted/etd.pdf.

9. Gabbard J, Hix D, Swan J. User-centered design and evaluation of virtual environments. IEEE Computer Graphics and Applications 1999; 19:51-9.

10. Federoff M. (2002) Heuristics and usability guidelines for the creation and evaluation of fun in video games. Available at: http://melissafederoff.com/heuristics_ usability_games.pdf.

11. Witmer B, Singer M. Measuring presence in virtual environments: a presence questionnaire. Presence: Teleoperator and Virtual Environments 1998; 7:225-40.

12. Palisano R, Rosenbaum P, Walter S, Russell D, Wood E, Galuppi B. Development and reliability of a system to classify gross motor function in children with cerebral palsy. Developmental Medicine and Child Neurology 1997; 39:214-23.

13. Eliasson AC, Krumlinde-Sundholm L., Rösblad B, Beckung E, Arner M, Ohrvall AM, Rosenbaum P. The Manual Ability Classification System (MACS) for children with cerebral palsy: scale development and evidence of validity and reliability. Dev Med Child Neurol 2006;48(7):549-54.

14. Zancolli E, Goldner L, Swanson A. Surgery of the spastic hand in cerebral palsy: report of the Committee on Spastic Hand Evaluation (International Federation of Societies for Surgery of the Hand). Journal of Hand Surgery 1983; 8:766-72.

15. Randall M, Carlin J, Chondros P, Reddihough D. Reliability of the Melbourne Assessment of unilateral upper limb function. Developmental Medicine and Child Neurology 2001; 43:761-7.

16. Johnson L, Randall M, Reddihough D, Oke L, Byrt T, Bach T. Development of a clinical assessment of quality of movement for unilateral upper-limb function. Developmental Medicine and Child Neurology 1994; 36:965-73.

17. Randall M, Johnson L, Reddihough D. (1999) The Melbourne Assessment of Unilateral Upper Limb Function: test administration manual. Melbourne, Australia

18. Weiss P, Rand D, Katz N, Kizony R. Video capture virtual reality as a flexible and effective rehabilitation tool. Journal of Neuroengineering Rehabilitation 2004; 1:12.

19. Holden MK. Virtual environments for motor rehabilitation: review. CyberPsychology \& Behavior 2005; 8:187-211.

Address reprint requests to: Dr. Michiel J. A. Jannink Roessingh Research and Development Roessinghsbleekweg 33b 7522 AH ENSCHEDE

E-mail: m.jannink@rrd.nl 